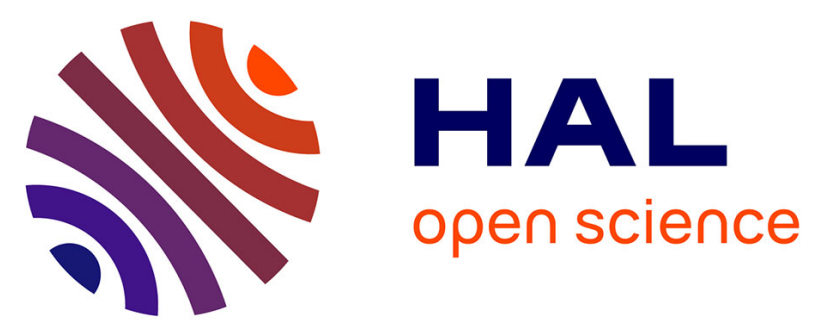

\title{
Early MRI in neonatal hypoxic-ischaemic encephalopathy treated with hypothermia: Prognostic role at 2-year follow-up
}

Valerie Charon, Maia Proisy, Gilles Bretaudeau, Bertrand Bruneau, Patrick Pladys, Alain Beuchee, Gladys Burnouf-Rose, Jean-Christophe Ferré, Celine Rozel

\section{To cite this version:}

Valerie Charon, Maia Proisy, Gilles Bretaudeau, Bertrand Bruneau, Patrick Pladys, et al.. Early MRI in neonatal hypoxic-ischaemic encephalopathy treated with hypothermia: Prognostic role at 2-year follow-up. European Journal of Radiology, 2016, 85 (8), pp.1366-1374. 10.1016/j.ejrad.2016.05.005 . hal-01361507

\section{HAL Id: hal-01361507 https://hal-univ-rennes1.archives-ouvertes.fr/hal-01361507}

Submitted on 7 Oct 2016

HAL is a multi-disciplinary open access archive for the deposit and dissemination of scientific research documents, whether they are published or not. The documents may come from teaching and research institutions in France or abroad, or from public or private research centers.
L'archive ouverte pluridisciplinaire HAL, est destinée au dépôt et à la diffusion de documents scientifiques de niveau recherche, publiés ou non, émanant des établissements d'enseignement et de recherche français ou étrangers, des laboratoires publics ou privés. 


\section{CONFLICTS OF INTEREST}

The authors have no conflict of interest to declare. 


\title{
Early MRI in neonatal hypoxic-ischaemic encephalopathy treated with hypothermia: prognostic role at 2-year follow-up
}

\author{
Valérie Charon $^{1,2}$, Maïa Proisy ${ }^{1}$, Gilles Bretaudeau ${ }^{3}$, Bertrand Bruneau ${ }^{1}$, Patrick \\ Pladys $^{4}$, Alain Beuchée ${ }^{4}$, Gladys Burnouf-Rose ${ }^{5}$, Jean-Christophe Ferré ${ }^{6}$, Céline Rozel ${ }^{1}$
}

\section{Corresponding Author : Valérie Charon}

va.charon@gmail.com; valerie.charon@chu-angers.fr

${ }^{1}$ CHU Rennes, Department of Paediatric Radiology, Hôpital Sud, 16 Boulevard de Bulgarie 35200 Rennes, France

${ }^{2}$ Permanent Adress : CHU Angers, Department of Paediatric Radiology, 4 rue Larrey, 49100 Angers, France

${ }^{3}$ CHU Rennes, Paediatrics department, Centre d'Action Médico-Sociale Précoce, Hôpital Pontchaillou, 2 rue Henri le Guilloux,

35000 Rennes, France

${ }^{4}$ CHU Rennes, Paediatrics department, Neonatology and CIC 1414, Hôpital Sud, 16 Boulevard de Bulgarie

35200 Rennes, France

${ }^{5}$ CHU Rennes, Paediatrics department, Centre Hospitalier Public du Cotentin, 2 Rue Aristide Briand, 50130 Cherbourg-Octeville, France

${ }^{6}$ CHU Rennes, Department of Neuroradiology, Hôpital Pontchaillou, 2 rue Henri le Guilloux, 35000 Rennes, France 


\title{
Early MRI in neonatal hypoxic-ischaemic encephalopathy treated with hypothermia: prognostic role at 2-year follow-up
}

\begin{abstract}
The prognostic role of early MRI ( $\leq 6$ days of life) is still uncertain in hypoxic-ischaemic encephalopathy (HIE) treated with hypothermia.

Objective - To compare the prognostic value of early ( $\leq 6$ days) and late MRIs ( $\geq 7$ days) in predicting adverse outcome at 2 years old in asphyxiated term neonates treated with hypothermia.

Methods - This retrospective study included all asphyxiated neonates eligible for hypothermia treatment between November 2009 and July 2012. Two MRI scans were performed at a median age of day 4 (early MRI) and day 11 (late MRI). Two radiologists analysed independently each MRI. Imaging was classified as normal/subnormal or abnormal, using a visual analysis. Apparent diffusion coefficient (ADC) values were measured within predefined areas and posterior limb of internal capsule (PLIC) signal intensity was analysed. Neurodevelopmental outcome was assessed at 18-41 months (median age 24 months) as favourable or adverse.

Results - Of the 38 neonates followed up, 8 had an adverse outcome, all related to abnormal MRIs. Twenty-nine neonates had both MRIs sequentially. Both early and late MRIs yielded $100 \%$ sensitivity for adverse outcome by using the visual analysis. Early MRI had a higher specificity than late MRI (96.3\% versus $89.3 \%)$. ADC measurements did not provide further information than visual analysis. PLIC signal abnormalities were a good predictor of adverse outcome on both MRIs.
\end{abstract}

Conclusion - Early MRI ( $\leq 6$ days) was a good predictor of neurodevelopmental outcome at 2 years old. It could reliably guide intensive care decisions after the end of hypothermia treatment. 


\title{
HighLights
}

Early ( $\leq 6$ days) and later MRIs were both good adverse outcome predictors in HIE Both MRIs had 100\% sensitivity for adverse outcome

Early MRI had higher specificity and positive predictive value than late MRI

Early MRI could reliably help parents and neonatologists with intensive care decisions

\section{KEYWORDS}

Neonates - Hypoxia-Ischaemia, Brain - Diffusion Magnetic Resonance Imaging Hypothermia, Induced - Patient Outcome Assessment

\author{
Abbreviations \\ HIE Hypoxic-Ischaemic Encephalopathy \\ MRI Magnetic Resonance Imaging \\ ADC Apparent Diffusion Coefficient \\ PLIC Posterior Limb of Internal Capsule \\ RBL Revised Brunet-Lezine \\ GMFCS Gross Motor Function Classification System \\ DQ Developmental Quotient \\ DWI Diffusion Weighted Imaging \\ PPWMI Punctate Periventricular White Matter Injuries \\ ROI Region Of Interest \\ ROC Receiver Operating Characteristic \\ AUC Area Under Curve \\ OR Odds Ratio \\ CI Confidence Interval
}




\section{INTRODUCTION}

Hypoxic-ischaemic encephalopathy (HIE) remains a major cause of term newborn death and neurological disability [1]. In neonates with moderate to severe HIE, whole-body hypothermia reduces mortality without increasing major neurodevelopmental disability in survivors at 18 months of age [2]. Clinical determination of prognosis was shown to be more difficult after hypothermia, particularly in the first four days of life [3]. Previous studies demonstrated that hypothermia treatment did not alter the good predictive value of magnetic resonance imaging (MRI) at 2 years of age, when performed in the first month of life [4-6].

Recent studies demonstrated that early MRI (performed in the first week of life) could reliably predict the extent and severity of brain injury observed on later MRI (performed after day 7 , considering the first day of life as day 1) in asphyxiated neonates treated with hypothermia [7-11]. Nevertheless, to our knowledge, the prognostic value of early and late MRI had not been compared in these neonates. Early reliable imaging assessment of brain injury with a good prognostic value could help neonatologists and parents with intensive care decisions after the end of hypothermia treatment. We worked on the assumption that the prognostic value of early and late MRI would be similar.

The primary objective of this study was to compare the prognostic value of early and late MRI for adverse outcome at 2 years of age in neonates suffering from HIE treated with whole-body hypothermia. The secondary objectives were to assess the prognostic value of apparent diffusion coefficient (ADC) measurements within predefined brain areas and the prognostic value of posterior limb of internal capsule (PLIC) signal abnormalities. 


\section{MATERIALS AND METHODS}

\section{Patients}

This retrospective study was approved by the local Ethics Committee. All parents signed a treatment authorization form and gave consent for imaging.

Consecutive neonates presenting with moderate or severe HIE in the neonatal intensive care unit of our university hospital between November 2009 and July 2012, and who were eligible for whole-body hypothermia based on the criteria of the French Society of Neonatology, were included (Table 1) [12]. The exclusion criteria were associated conditions that could influence outcome (major congenital abnormalities, genetic anomalies with neurodevelopmental retardation) and neonatal stroke.

Hypothermia was to be induced within the first 6 hours after birth and continued for 72 hours, with a target temperature between 33 and $34^{\circ} \mathrm{C}$.

\section{Neurodevelopmental outcome}

All surviving neonates were evaluated by an experienced paediatric neurologist (X.X.) between 18 and 41 months and given a detailed neurodevelopmental examination. Neurodevelopmental outcome was assessed using the Revised Brunet-Lezine (RBL) scale whenever possible and the GMFCS (Gross Motor Function Classification System). The RBL scale is an early childhood psychomotor development scale covering four areas of neurodevelopment: movement and posture, coordination, language, and sociability. Four subscores can be calculated for each neurodevelopmental area and yield a global developmental quotient (DQ). This scale can be used for children aged from 2 to 30 months [14]. After 30 months, the RBL scale could not be used and the neurodevelopmental assessment was based on a detailed neurological assessment and GMFCS for motor outcome.

Favourable outcome was defined as either a normal neurological assessment (global DQ>85 when available, no cerebral palsy, no impact on day-to-day living) or mild to moderate neurological impairment (global $\mathrm{DQ}=70-85$, and/or GMFCS level I to II, low impact on day-to-day living). Adverse outcome was defined as death or major disability (global DQ<70, and/or GMFCS level III to V, and/or significant impact on day-to-day living). 


\section{MRI acquisition}

The MRI scans were performed as close as possible to day 4, on completion of hypothermia (early MRI), and day 11 (late MRI).

MR imaging was performed on a $1.5 \mathrm{~T}$ whole-body system (Magnetom Symphony, Siemens Healthcare, Erlangen, Germany).

The imaging protocol included the following sequences: three-dimensional T1weighted gradient echo (repetition time (TR)/echo time (TE)/inversion time (TI), 2040/3.9/1100 ms, slice thickness $1 \mathrm{~mm}$ ) or T1-weighted spin echo in the axial, sagittal and coronal planes (TR/TE, 446-627/16-25 ms, slice thickness $4 \mathrm{~mm}$ ), T2-weighted turbo spinecho in the axial, sagittal and coronal planes (TR/TE, 4600-6490/90-103 ms, slice thickness $4 \mathrm{~mm}$ ), and echo-planar-based diffusion-weighted imaging (DWI) (TR/TE, 2900-4000/81-99 $\mathrm{ms}, \mathrm{b}$ values of 0 and $1000 \mathrm{~s} / \mathrm{mm} 2$, slice thickness $5 \mathrm{~mm}$ ) with automatically generated ADC maps.

Two different receive-only coils were used depending on neonate weight or whether the neonate was ventilated: knee or head coils. The knee coil did not enable three-dimensional imaging.

\section{Image analysis}

Two experienced paediatric radiologists (X.X. and X.X., 6 and 13 years' experience) independently assessed MR images using OsiriX ${ }^{\circledR}$ software (Pixmeo, Geneva, Switzerland). Early and late MRIs were assessed independently. The reviewers were blinded to the clinical details and outcome of the neonates but knew the age at the time of MRI. The differences were then resolved by consensus between the two reviewers.

\section{Visual analysis of brain injury}

Assessment of brain injury was based on a previously described simplified classification (Appendix) [11]. It distinguished normal/subnormal MR images including normal MRI, punctate periventricular white matter injuries (PPWMI) and watershed pattern with a Watershed (W) score $\leq 2$ on the scoring system described by Barkovich et al. (single infarction or abnormal signal in anterior or posterior watershed white matter) [15], and abnormal MRI including watershed pattern with $\mathrm{W}$ score $>2$, central or diffuse patterns. Interobserver agreement is excellent (100\%) according to this classification [11]. 


\section{ADC measurements}

ADC measurements were performed bilaterally in 8 brain regions on ADC maps by a paediatric radiologist (X.X.) using OsiriX ${ }^{\circledR}$ software (Pixmeo, Geneva, Switzerland) (Figure $1)$.

Regions of interest (ROIs) were placed in the middle third of the PLIC, anterolateral thalami, lentiform nuclei in the putamen, head of caudate nuclei, frontal and parietal-occipital white matter at the level of the basal ganglia, semi-oval centres and cerebral peduncles in the brain stem. These regions were chosen for their propensity to ischaemic damage with a hypoxic injury $[16,17]$. The area of the regions of interest was $12-14 \mathrm{~mm}^{2}$ (circular ROIs), except in the PLIC where it was $4-6 \mathrm{~mm}^{2}$ (square ROIs). The mean ADC values of the right and left side were averaged for further analysis.

\section{Analysis of PLIC signal abnormalities}

We analysed changes in PLIC signal intensity as it is known to be a good predictor of unfavourable outcome and brain injury on late imaging [18]. PLIC signal intensity was considered as normal, equivocal or abnormal on the T1- and T2-weighted images and on DWI, according to the same criteria as those described by Rutherford et al., with PLIC hyperintensity on the DWI considered as an additional abnormal aspect.

As normal signal intensity within the PLIC is related to its degree of myelination, we focused on neonates with a corrected gestational age of over 40 weeks at the time of imaging [18].

\section{Statistical analysis}

Data were analysed using MedCalc statistical software (version 12.5, Ostend, Belgium).

Clinical and biological features were compared between groups by Fisher's exact test for categorical data, and Mann-Whitney U test for continuous data.

The relationship between the results of each MRI on visual analysis and neurological outcome was assessed by Fisher's exact test. We calculated the predictive values for adverse outcome at 2 years of age for each MRI among all the neonates with available follow-up data and among neonates who had undergone both early and late MRIs sequentially. Predictive values were provided with $95 \%$ CIs.

The ability of ADC measurements on early MRI in predicting adverse outcome at 2 years of age was assessed using receiver operating characteristic (ROC) curves. The results 
were presented as areas under curves (AUCs) and odds ratios (ORs) with 95\% confidence intervals (CIs) using logistic regression.

Finally, we calculated the predictive values for adverse outcome at 2 years of age for PLIC signal abnormalities on both MRIs.

We considered $p<0.05$ as indicating a significant difference.

\section{RESULTS}

Fifty neonates were treated with hypothermia for HIE between November 2009 and July 2012 (Figure 2).

Seven neonates were excluded. Five neonates were lost to follow-up before 18 months of age $(11.6 \%)$. Among these cases, one had abnormal early and late MRIs. The others had normal readings or PPWMI on early and/or late MRIs.

\section{Neonates' characteristics and outcome}

The mean gestational age of the 38 included neonates was 39 weeks and 4 days (range 3641+6). Thirty-two early MRIs were performed at a median age of day 4 (range 3-6), and 35 late MRIs at a median age of day 11 (range 7-21). Twenty-nine neonates underwent both MRIs (76.3\%).

Thirty neonates had a favourable outcome and 8 neonates had an adverse outcome (Figure 2).

Neonates with an adverse outcome had a significantly higher birth weight, but lower cord $\mathrm{pH}$ level than those with a favourable outcome (Table 2). There was no difference in other criteria of asphyxia between the two groups.

Seven surviving neonates could not be assessed with the RBL scale; they were yet evaluated by GMFCS. All of them had a favourable outcome. 


\section{Prognostic value of early and late MRIs' visual analysis in predicting adverse outcome}

\section{Results of early and late MRI in each outcome group}

The results of MRI, particularly the patterns of injury, were significantly different in the two outcome groups for both MRIs (Table 3).

In the adverse outcome group, all the neonates had abnormal MRIs with central or diffuse injuries on both early and late imaging.

In the favourable outcome group, only one neonate had an abnormal early MRI with diffuse injuries. His late MRI was also abnormal (Figure 3).

Late MRI was abnormal for two other neonates with a favourable outcome. They had moderate central injuries with mild signal abnormalities in the thalami and/or lentiform nuclei, which were not visible on early MRI performed at day 5. The neurological assessment was normal for one of these neonates at 23.3 months $(D Q=100)$. The second neonate had a normal motor development but a moderate language delay and some behavioral disorders with autism spectrum disorders, corresponding to a mild neurological impairment. He was assessed at 24,1 months, but as he did not cooperate for examination, we could not obtain a developmental quotient (Figure 4).

Four other neonates had mild to moderate neurological impairments, but their MRIs were normal/subnormal. The patterns of injury in neonates with mild to moderate neurological impairment were not significantly different from those with normal neurological assessment as determined by Fisher's exact test (not shown).

\section{Prognostic value of abnormal early and late MRIs in predicting adverse outcome at 2 years of age}

Early and late MRIs were both good predictors of outcome with $100 \%$ sensitivity and negative predictive value (Table 4).

Specificity and positive predictive value were lower than sensitivity and negative predictive value but remained good. Among all neonates with available follow-up data, they were slightly higher for early MRI (respectively $96.3 \%$ and $83.3 \%$ ) than for late MRI $(89.3 \%$ and 70\%). Similarly, among the 29 neonates who had undergone both MRIs sequentially, the specificity and positive predictive value were slightly higher for early MRI (96\% and 80\%) than for late MRI ( $88 \%$ and $57.1 \%)$. 


\section{ADC measurements on early MRI}

ADC measurements were good predictors of outcome on early MRI, according to the ROC analysis presented in Table 5. The best predictors of neurological outcome with the highest AUCs were ADC values within the posterior white matter, semi-oval centres and PLIC.

Both neonates who had normal early MRI and moderate central injuries on late MRI had ADC values above the cut-off value within the lentiform nuclei $\left(1.0810^{-9} / \mathrm{mm}^{2} / \mathrm{s}\right.$ and 1.07 $\left.10^{-9} / \mathrm{mm}^{2} / \mathrm{s}\right)$, and likewise in the thalami $\left(1.1810^{-9} / \mathrm{mm}^{2} / \mathrm{s}\right.$ and $\left.1.1610^{-9} / \mathrm{mm}^{2} / \mathrm{s}\right)$.

The neonate with diffuse injuries on both MRIs and a favourable outcome had ADC values below the cut-off value in all regions except the thalami $\left(0.9210^{-9} / \mathrm{mm}^{2} / \mathrm{s}\right.$ within the thalami; $0.8210^{-9} / \mathrm{mm}^{2} / \mathrm{s}$ within the PLIC; $0.9510^{-9} / \mathrm{mm}^{2} / \mathrm{s}$ within the lentiform nuclei; 1.24 $10^{-9} / \mathrm{mm}^{2} / \mathrm{s}$ within frontal white matter; $1.0310^{-9} / \mathrm{mm}^{2} / \mathrm{s}$ within posterior white matter; 0.95 $10^{-9} / \mathrm{mm}^{2} / \mathrm{s}$ within the semi ovale center).

\section{Abnormal signal intensity within the PLIC and outcome}

Abnormal signal intensity within the PLIC was a good predictor of outcome for neonates with a corrected gestational age of over 40 weeks at the time of imaging.

PLIC signal abnormalities on late MRI predicted an adverse outcome with $100 \%$ sensitivity (95\% CI [54-100]) and 100\% specificity (95\% CI [84.4-100]). For early MRI, sensitivity was also excellent (100\% with 95\% CI [47.9-100]), but specificity was lower (80\% with 95\% CI [51.9-95.4]). Three neonates in the favourable outcome group had an abnormal or equivocal PLIC appearance on early MRI on T1-weighted images. One of them showed also high intensity on DWI. However, ADC values within the PLIC were higher than $0.9610^{-}$ $9 / \mathrm{mm}^{2} / \mathrm{s}$ in the three cases. Late MRI with similar imaging paramaters was performed for two of these neonates, in which PLIC signal intensity was normal.

PLIC signal intensity was normal on both MRIs for the neonates with abnormal early and/or late imaging and a favourable outcome. 


\section{Discussion}

The results from this study demonstrated that early and late MRI were both good predictors of death or major disability at 2 years of age, with $100 \%$ sensitivity. Early MRI offered better specificity than late MRI. ADC measurements and an abnormal PLIC appearance were also good predictors of adverse outcome on early MRI. These results are relevant because the availability of early reliable prognostic information is important to help neonatologists and parents with intensive care decisions after the end of hypothermia treatment.

We reported excellent $100 \%$ sensitivity and negative predictive values, and good specificity and positive predictive values $(96.3 \%$ and $83.3 \%$ for early MRI; $89.3 \%$ and $70 \%$ for late MRI) for both MRIs using the simplified classification. Previous studies reported results similar to ours in neonates treated with hypothermia, but with more variation in MRI timing (MRI performed in the first month of life) $[4,6]$. They also found excellent sensitivity $(88-90 \%)$ and negative predictive value (91\%), as well as lower specificity (65-82\%) and positive predictive value $(62-76 \%)$.

In our study, the lower specificity of MRI was due to one case of diffuse brain injury visible on both MRIs and two cases of moderate central injuries visible on late MRI only, with an unexpected favourable outcome. Central injuries and more extensive or diffuse injuries are known to be associated with a poor prognosis with or without hypothermia treatment; but some moderate central injuries and, more rarely, diffuse injuries have been observed in neonates with a normal neurodevelopmental outcome [4-6,19-25].

Some studies suggested that early MRI, and particularly DWI, could underestimate brain lesions [26-29]. We actually observed two cases with normal early MRI, but central injuries on late MRI, yet associated with a good prognosis. One of these neonates had yet a moderate language delay and some behavioural disorders, and need a close follow-up by paediatric neurologist. It could be of great importance to detect this kind of subtle brain injuries on a late MRI systematically performed when early MRI is normal, in order to adapt the neurodevelopmental follow up during the first years of life.

Surprisingly, we observed two other cases with similar moderate central injuries visible on late imaging, with an adverse outcome. However, they both had abnormal early MRIs with the injuries visible to the same or a greater extent on DWI. These observations support the idea that early MRI is a good predictor of outcome, and in these cases was a better predictor than late MRI. 
The strength of our study lies in the sequential performance of early and late MRI for a large number of the neonates included (76.3\%). Among the 29 neonates who had both MRIs and among all the neonates followed up (38 neonates), we reported similar good predictive values for both MRIs. It was interesting to focus on neonates who had undergone sequential early and late MRIs. Indeed, the predictive values of each MRI were more comparable as they involved the same population.

To our knowledge, no previous article has compared the predictive values of early and late MRIs for death or severe neurological impairment at 2 years of age including so many patients treated with hypothermia. In this study, we confirmed that early MRI had a predictive value at least as good as late MRI, as was expected given the excellent agreement between early and late MRIs [8-11]. Our results were inconsistent with the results of a meta-analysis which suggested that the discriminatory power of late MRI (days 8-30) was higher than that of early MRI (days 1-7), with late MRI showing higher sensitivity (99\%) than early MRI (85\%) [30]. However, early MRI assessment was based on studies relating to non-cooled neonates who underwent only one MRI, with a small number of patients ( $\leq 26$ neonates) and a generally shorter follow-up interval (12 months).

Focusing on the selected area, the ADC values of early MRI were consistent with the outcome. The highest AUCs were obtained for ADC values within the posterior white matter, semi-oval centres and PLIC, with excellent sensitivity but lower specificity for most of the areas. Previous studies, which mainly focused on non-cooled neonates, demonstrated higher specificity of ADC measurements, particularly in the basal ganglia and PLIC [17,21,23,3134].

In our study, the ADC measurements added little to the visual analysis as a prognostic tool. The only case with abnormal early MRI and a favourable outcome had a lowered ADC in all areas except for the thalami, which confirmed the visual impression of reduced diffusivity. $\mathrm{ADC}$ was not reduced in the thalami because ADC measurements concerned the anterolateral thalami, whereas the posterior part of the thalami was affected on DWI.

Several cut-off values of ADC with $100 \%$ positive predictive value of poor outcome have been suggested in the literature mainly in the lentiform nuclei and PLIC [17,33-35]. With all these cut-off values, the positive predictive value of ADC remained low in our study. This highlights the poor inter-scanner ADC quantification reproducibility.

However, these studies mostly concerned non-cooled neonates. One limitation to the interpretation of our results regarding the prognostic value of ADC measurements was the 
performance of early MRI during hypothermia for 4 neonates. ADC values depend on

There are limitations to our study. Early MRI could not be performed at the same time for all neonates, due either to a worrying condition or organisational issues. However, early MRIs were all performed between days 3 and 6 , and it has been described that greatest reduction in diffusivity was observed between days 2 and 6 in cooled neonates [36].

The number of patients included was small. We therefore had to separate the neonates into two outcome groups (favourable or adverse) for the results about the prognostic value of MRI to be significant and reliable.

In addition, there was a small number of neonates with an adverse outcome. Surprisingly, we observed a lower rate of neonates with an adverse outcome $(21 \%)$ than in previous studies including a greater number of patients (30-46\%) [4-6]. In our study, there were yet more neonates with severe encephalopathy than in two out of three of these studies (46\% versus $21-25 \%$ ) [5,6]. Moreover, only two neonates in the adverse outcome group 
survived. This low rate of surviving neonates could be related to certain decisions to forgo including imaging.

The retrospective design of our study induced certain limitations, as the wide followup range (18-41 months). Yet, the median time to follow-up remained within our limit of two years of age. There were also some technical limitations previously identified, particularly as we used two different coils with different parameters for T1-weighted imaging[11]. Moreover, advanced MRI techniques such as spectroscopy and diffusion tensor imaging were not available in our center during the study period. In combination with conventional imaging and DWI, they would likely be even more valuable in predicting outcome.

\section{CONCLUSION}

Early MRI including diffusion-weighted imaging is a good predictor of adverse outcome in HIE treated with hypothermia, yielding a sensitivity of $100 \%$ based on a simple visual analysis. It tended to be a better predictor of outcome than late MRI. ADC measurements might help to confirm reduced diffusivity but did not provide any valuable additional information than simple visual analysis in predicting neurological outcome, whereas the analysis of PLIC appearance was seen to help in predicting neurological outcome on both MRIs.

Early MRI could be a reliable aid for managing intensive care treatment and parent counselling since a normal/subnormal MRI would offer a reassuring prognosis. However, late MRI should still be systematically performed when early MRI is normal, in order to detect more subtle injuries that might induced mild to moderate neurological impairments needing a closer follow-up. When early MRI is abnormal, this study has shown that prognostication should be made with cautious (as favourable outcome is still possible), but that repeating a later MRI added little, if any, further information.

Further studies with a larger number of neonates and longer follow-up are needed, particularly involving the addition of clinico-biological, electrophysiological intensive care data, and advanced MRI techniques. 


\section{REFERENCES}

[1] G. Dixon, N. Badawi, J.J. Kurinczuk, J.M. Keogh, S.R. Silburn, S.R. Zubrick, et al., Early Developmental Outcomes After Newborn Encephalopathy, Pediatrics. 109 (2002) $26-33$.

[2] S.E. Jacobs, M. Berg, R. Hunt, W.O. Tarnow-Mordi, T.E. Inder, P.G. Davis, Cooling for newborns with hypoxic ischaemic encephalopathy, Cochrane Database Syst. Rev. 1 (2013) CD003311.

[3] A.J. Gunn, J.S. Wyatt, A. Whitelaw, J. Barks, D. Azzopardi, R. Ballard, et al., Therapeutic hypothermia changes the prognostic value of clinical evaluation of neonatal encephalopathy, J. Pediatr. 152 (2008) 55-58, 58.e1.

[4] M. Rutherford, L.A. Ramenghi, A.D. Edwards, P. Brocklehurst, H. Halliday, M. Levene, et al., Assessment of brain tissue injury after moderate hypothermia in neonates with hypoxic-ischaemic encephalopathy: a nested substudy of a randomised controlled trial, Lancet Neurol. 9 (2010) 39-45.

[5] J.L.Y. Cheong, L. Coleman, R.W. Hunt, K.J. Lee, L.W. Doyle, T.E. Inder, et al., Prognostic utility of magnetic resonance imaging in neonatal hypoxic-ischemic encephalopathy: substudy of a randomized trial, Arch. Pediatr. Adolesc. Med. 166 (2012) 634-640.

[6] S. Shankaran, P.D. Barnes, S.R. Hintz, A.R. Laptook, K.M. Zaterka-Baxter, S.A. McDonald, et al., Brain injury following trial of hypothermia for neonatal hypoxicischaemic encephalopathy, Arch. Dis. Child. Fetal Neonatal Ed. 97 (2012) F398-404.

[7] P. Wintermark, A. Hansen, J. Soul, M. Labrecque, R.L. Robertson, S.K. Warfield, Early versus late MRI in asphyxiated newborns treated with hypothermia, Arch. Dis. Child. Fetal Neonatal Ed. 96 (2011) F36-44. doi:10.1136/adc.2010.184291.

[8] T. Agut, M. León, M. Rebollo, J. Muchart, G. Arca, A. Garcia-Alix, Early identification of brain injury in infants with hypoxic ischemic encephalopathy at high risk for severe impairments: accuracy of MRI performed in the first days of life, BMC Pediatr. 14 (2014) 177. doi:10.1186/1471-2431-14-177.

[9] J.H. Skranes, F.M. Cowan, T. Stiris, D. Fugelseth, M. Thoresen, A. Server, Brain imaging in cooled encephalopatic neonates does not differ between four and 11 days after birth, Acta Paediatr. Oslo Nor. 1992. (2015). doi:10.1111/apa.13016. 
[10] E. Boudes, X. Tan, C. Saint-Martin, M. Shevell, P. Wintermark, MRI obtained during versus after hypothermia in asphyxiated newborns, Arch. Dis. Child. Fetal Neonatal Ed. 100 (2015) F238-242.

[11] V. Charon, M. Proisy, J.-C. Ferré, B. Bruneau, C. Tréguier, A. Beuchée, et al., Comparison of early and late MRI in neonatal hypoxic-ischemic encephalopathy using three assessment methods, Pediatr. Radiol. 45 (2015) 1988-2000.

[12] E. Saliba, T. Debillon, Neuroprotection par hypothermie contrôlée dans l'encéphalopathie hypoxique-ischémique du nouveau-né à terme, Arch. Pédiatrie. 17, Supplement 3 (2010) S67-S77.

[13] H.B. Sarnat, M.S. Sarnat, Neonatal encephalopathy following fetal distress. A clinical and electroencephalographic study, Arch. Neurol. 33 (1976) 696-705.

[14] O. Brunet, I. Lézine, D. Josse, Brunet-Lézine révisé: échelle de développement psychomoteur de la première enfance, Etablissements d'Applications Psychotechniques, Issy-Les-Moulineaux, France, 1997.

[15] A.J. Barkovich, B.L. Hajnal, D. Vigneron, A. Sola, J.C. Partridge, F. Allen, et al., Prediction of neuromotor outcome in perinatal asphyxia: evaluation of MR scoring systems, AJNR Am. J. Neuroradiol. 19 (1998) 143-149.

[16] J.S. Coats, A. Freeberg, E.G. Pajela, A. Obenaus, S. Ashwal, Meta-analysis of apparent diffusion coefficients in the newborn brain, Pediatr. Neurol. 41 (2009) 263-274.

[17] L. Liauw, G. van Wezel-Meijler, S. Veen, M.A. van Buchem, J. van der Grond, Do apparent diffusion coefficient measurements predict outcome in children with neonatal hypoxic-ischemic encephalopathy?, AJNR Am. J. Neuroradiol. 30 (2009) 264-270.

[18] M.A. Rutherford, J.M. Pennock, S.J. Counsell, E. Mercuri, F.M. Cowan, L.M. Dubowitz, et al., Abnormal magnetic resonance signal in the internal capsule predicts poor neurodevelopmental outcome in infants with hypoxic-ischemic encephalopathy, Pediatrics. 102 (1998) 323-328.

[19] M. Martinez-Biarge, J. Diez-Sebastian, O. Kapellou, D. Gindner, J.M. Allsop, M.A. Rutherford, et al., Predicting motor outcome and death in term hypoxic-ischemic encephalopathy, Neurology. 76 (2011) 2055-2061.

[20] C. Kuenzle, O. Baenziger, E. Martin, L. Thun-Hohenstein, M. Steinlin, M. Good, et al., Prognostic value of early MR imaging in term infants with severe perinatal asphyxia, Neuropediatrics. 25 (1994) 191-200.

[21] C. Boichot, P.M. Walker, C. Durand, M. Grimaldi, S. Chapuis, J.B. Gouyon, et al., Term neonate prognoses after perinatal asphyxia: contributions of MR imaging, MR 
spectroscopy, relaxation times, and apparent diffusion coefficients, Radiology. 239 (2006) 839-848.

[22] V. Jadas, M. Brasseur-Daudruy, C. Chollat, L. Pellerin, A.M. Devaux, S. Marret, et al., [The contribution of the clinical examination, electroencephalogram, and brain MRI in assessing the prognosis in term newborns with neonatal encephalopathy. A cohort of 30 newborns before the introduction of treatment with hypothermia], Arch. Pédiatrie Organe Off. Sociéte Fr. Pédiatrie. 21 (2014) 125-133.

[23] E. Twomey, A. Twomey, Stephanie Ryan, J. Murphy, V.B. Donoghue, MR imaging of term infants with hypoxic-ischaemic encephalopathy as a predictor of neurodevelopmental outcome and late MRI appearances, Pediatr. Radiol. 40 (2010) $1526-1535$.

[24] B.J.M. van Kooij, M. van Handel, R.A.J. Nievelstein, F. Groenendaal, M.J. Jongmans, L.S. de Vries, Serial MRI and neurodevelopmental outcome in 9- to 10-year-old children with neonatal encephalopathy, J. Pediatr. 157 (2010) 221-227.e2.

[25] P.-L. Khong, C. Tse, I.Y.C. Wong, B.C.C. Lam, P.-T. Cheung, W.H.S. Goh, et al., Diffusion-weighted imaging and proton magnetic resonance spectroscopy in perinatal hypoxic-ischemic encephalopathy: association with neuromotor outcome at 18 months of age, J. Child Neurol. 19 (2004) 872-881.

[26] A.J. Barkovich, S.P. Miller, A. Bartha, N. Newton, S.E.G. Hamrick, P. Mukherjee, et al., MR imaging, MR spectroscopy, and diffusion tensor imaging of sequential studies in neonates with encephalopathy, AJNR Am. J. Neuroradiol. 27 (2006) 533-547.

[27] R.L. Robertson, L. Ben-Sira, P.D. Barnes, R.V. Mulkern, C.D. Robson, S.E. Maier, et al., MR line-scan diffusion-weighted imaging of term neonates with perinatal brain ischemia, AJNR Am. J. Neuroradiol. 20 (1999) 1658-1670.

[28] R.C. McKinstry, J.H. Miller, A.Z. Snyder, A. Mathur, G.L. Schefft, C.R. Almli, et al., A prospective, longitudinal diffusion tensor imaging study of brain injury in newborns, Neurology. 59 (2002) 824-833.

[29] M. Rutherford, S. Counsell, J. Allsop, J. Boardman, O. Kapellou, D. Larkman, et al., Diffusion-weighted magnetic resonance imaging in term perinatal brain injury: a comparison with site of lesion and time from birth, Pediatrics. 114 (2004) 1004-1014.

[30] S. Thayyil, M. Chandrasekaran, A. Taylor, A. Bainbridge, E.B. Cady, W.K.K. Chong, et al., Cerebral magnetic resonance biomarkers in neonatal encephalopathy: a metaanalysis, Pediatrics. 125 (2010) e382-395. 
[31] F. Cavalleri, L. Lugli, M. Pugliese, R. D’Amico, A. Todeschini, E. Della Casa, et al., Prognostic value of diffusion-weighted imaging summation scores or apparent diffusion coefficient maps in newborns with hypoxic-ischemic encephalopathy, Pediatr. Radiol. 44 (2014) 1141-1154.

[32] S.K. Goergen, H. Ang, F. Wong, E.A. Carse, M. Charlton, R. Evans, et al., Early MRI in term infants with perinatal hypoxic-ischaemic brain injury: interobserver agreement and MRI predictors of outcome at 2 years, Clin. Radiol. 69 (2014) 72-81.

[33] T. Alderliesten, L.S. de Vries, M.J.N.L. Benders, C. Koopman, F. Groenendaal, MR imaging and outcome of term neonates with perinatal asphyxia: value of diffusionweighted MR imaging and ${ }^{1}$ H MR spectroscopy, Radiology. 261 (2011) 235-242.

[34] R.J. Vermeulen, P.E.M. van Schie, L. Hendrikx, F. Barkhof, M. van Weissenbruch, D.L. Knol, et al., Diffusion-weighted and conventional MR imaging in neonatal hypoxic ischemia: two-year follow-up study, Radiology. 249 (2008) 631-639.

[35] O. Brissaud, M. Amirault, F. Villega, O. Periot, J.F. Chateil, M. Allard, Efficiency of fractional anisotropy and apparent diffusion coefficient on diffusion tensor imaging in prognosis of neonates with hypoxic-ischemic encephalopathy: a methodologic prospective pilot study, AJNR Am. J. Neuroradiol. 31 (2010) 282-287.

[36] N. Bednarek, A. Mathur, T. Inder, J. Wilkinson, J. Neil, J. Shimony, Impact of therapeutic hypothermia on MRI diffusion changes in neonatal encephalopathy, Neurology. 78 (2012) 1420-1427. 


\section{FIGURES LEGENDS}

Fig. 1 a-c Placement of the regions of interest for measurement of apparent diffusion coefficient values in the semi-oval centres (a), frontal white matter, head of caudate nuclei, lentiform nuclei, posterior limb of internal capsule, anterolateral thalami, parietal-occipital white matter (b) and cerebral peduncles (c)

Fig. 2 Flow chart of patients

Fig. 3 a-f Male neonate of $41+6$ weeks' gestation with diffuse injuries on early MRI at day 4 (a-c) and late MRI at day 9 (d-f) and a favourable outcome (normal neurological assessment at 23 months with a global developmental quotient of 97). a-b Early diffusion-weighted imaging (DWI) and corresponding apparent diffusion coefficient maps with hyperintensity in the hippocampi (bottom arrows), the thalami (top arrows) (a), and the perirolandic, frontal and parietal white matter (arrows) (b). c Axial T1-weighted imaging with hyperintensity in the bilateral insular cortex (arrows). d Axial T2-weighted images on late MRI with mild hyperintensity in the thalami (arrows). e-f Axial T1weighted images on late MRI with normal hyperintensity within the PLIC (arrows), mild intraventricular haemorrhage in the left occipital ventricular horn $\left(^{*}\right)(e)$ and hyperintensity within the insular cortex (arrows) (f)

Fig. 4 a-d Female neonate of 39 weeks' gestation with normal early MRI, abnormal late MRI (moderate central lesions) and a favourable outcome. a-b Normal early imaging (day 5) at the level of the basal ganglia with axial diffusion-weighted imaging (a), and axial T2-weighted imaging (b); PLIC signal intensity was normal (arrows). c-d Late imaging (day 12) at the same level with mild hyperintensity on axial T1-weighted images within the thalami (bottom arrows) and normal hyperintensity within the PLIC (top arrows) (c) and axial T2-weighted images with hyperintensity within the thalami (bottom arrows) and the posterior part of the lentiform nuclei (top arrows) (d) 


\section{TABLES LEGENDS}

Table 1. Eligibility criteria for whole body hypothermia (French Society of Neonatology)

Table 2 Neonates' characteristics for the two outcome groups

Table 3 Results of early and late MRIs in favourable and adverse outcome groups

Table 4 Prognostic capability of abnormal MRI in predicting adverse outcome at 2 years of age according to the simplified classification for all neonates followed up in the study and for neonates who had both MRIs sequentially

Table 5 Receiver operating characteristic analysis using ADC values on early MRI as a predictor of adverse outcome at 2 years of age (32 neonates assessed) 


\section{ACKNOWLEDGEMENTS}

The authors would like to thank Dr. Jennifer Chauvel for her contribution to data collection and Mrs. Tracey Westcott for her editorial assistance. 
Gestational age $\geq 36$ weeks

Birth weight $\geq 1800 \mathrm{~g}$

Signs of perinatal asphyxia

- Acute perinatal event (severe foetal heart rate abnormalities, cord prolapse, placental abruption, etc.)

- And at least one of the following criteria:

- Apgar score $\leq 5$ at 10 minutes

- Mechanical ventilation or intubation at 10 minutes of life

- Metabolic acidosis (within 60 minutes of birth)

- cord, arterial, venous or capillary blood $\mathrm{pH}<7$

- $\quad$ or base deficit $\geq 16 \mathrm{mmol} / \mathrm{L}$

- $\quad$ or lactate level $\geq 11 \mathrm{mmol} / \mathrm{L}$

Moderate or severe encephalopathy (in terms of clinical staging as described by Sarnat and Sarnat

[13] and electrical features if available) 


\begin{tabular}{|c|c|c|c|c|c|}
\hline & $\begin{array}{l}\text { Number } \\
\text { of patients }\end{array}$ & $\begin{array}{l}\text { Favourable } \\
\text { outcome }\end{array}$ & $\begin{array}{l}\text { Number } \\
\text { of patients }\end{array}$ & Adverse outcome & p value \\
\hline Gestational age $(w+d)$ & 30 & $39+5(38+2-40+6)$ & 8 & $40+2(39+4-41)$ & 0.267 \\
\hline Birth weight (g) & 30 & $3170(2775-3460)$ & 8 & $3600(3070-3872,5)$ & 0.049 \\
\hline Male sex & 30 & $17(57)$ & 8 & $3(37)$ & 0.438 \\
\hline Mode of delivery & 30 & & 8 & & \multirow{3}{*}{0.693} \\
\hline Spontaneous birth & & $16(53)$ & & $3(37)$ & \\
\hline Caesarean & & $14(47)$ & & $5(63)$ & \\
\hline $\begin{array}{l}\text { Severity of encephalopathy } \\
\text { before hypothermia }\end{array}$ & 23 & & 8 & & \multirow{3}{*}{0.097} \\
\hline Moderate & & $15(65)$ & & $2(25)$ & \\
\hline Severe & & $8(35)$ & & $6(75)$ & \\
\hline $\begin{array}{l}\text { Meconium-stained amniotic } \\
\text { fluid }\end{array}$ & 29 & $21(72)$ & 7 & $2(29)$ & 0.073 \\
\hline $\begin{array}{l}\text { Anticonvulsants in intensive } \\
\text { care unit }\end{array}$ & 29 & $19(66)$ & 8 & $8(100)$ & 0.078 \\
\hline Cord pH level & 21 & $7(6.93-7.18)$ & 4 & $6.80(6.8-6.89)$ & 0.041 \\
\hline pH level $1 \mathrm{~h}$ & 24 & $7.26(7.08-7.33)$ & 8 & $7.25(7.12-7.30)$ & 0.811 \\
\hline Lactate level $1 \mathrm{~h}(\mathrm{mmol} / \mathrm{L})$ & 23 & $8.7(4.78-13.53)$ & 8 & $13.10(7.9-15.2)$ & 0.191 \\
\hline Base deficit, (mmol/L) & 17 & $9(4.75-13.5)$ & 7 & $12(5.25-16)$ & 0.546 \\
\hline 5-minute Apgar score & 29 & $4(3-5)$ & 8 & $3.5(1.5-4.5)$ & 0.400 \\
\hline 10-minute Apgar score & 26 & $5.5(4-7)$ & 8 & $5(4-6.5)$ & 0.582 \\
\hline Time of first MRI (d) & 27 & $4(4-5)$ & 5 & $4(4-4)$ & 0.270 \\
\hline Time of second MRI (d) & 28 & $12(10.5-14)$ & 7 & $9(9-11)$ & 0.014 \\
\hline Age at follow-up (m) & 30 & $24(23.5-26.8)$ & 2 & $23.6(22.9-24.3)$ & 0.392 \\
\hline Death & 30 & $0(0)$ & 8 & $6(75)$ & - \\
\hline Global DQ - med (range) & 23 & $97(78.5-109)$ & 2 & $57(52-62)$ & - \\
\hline Posture DQ & & $98(55-118)$ & & $52.5(36-69)$ & - \\
\hline Coordination DQ & & $99(83-117)$ & & $49(35-63)$ & - \\
\hline Language DQ & & $89(71-115)$ & & $61(49-73)$ & - \\
\hline Sociability DQ & & $100(70-111)$ & & $68(67-69)$ & - \\
\hline
\end{tabular}

Continuous and ordinal data are expressed as median (interquartile range), categorical data are expressed as number of patients (\%), except when specified $D Q=$ developmental quotient 


\begin{tabular}{|c|c|c|c|c|c|c|c|}
\hline & \multirow[b]{2}{*}{$\begin{array}{l}\text { Pattern of } \\
\text { injury }\end{array}$} & \multicolumn{3}{|c|}{ Early MRI $(\mathbf{N}=32)$} & \multicolumn{3}{|c|}{ Late MRI $(\mathbf{N}=35)$} \\
\hline & & $\begin{array}{l}\text { Favourable } \\
\text { outcome }^{\dagger} \\
(\mathrm{N}=27)\end{array}$ & $\begin{array}{l}\text { Adverse } \\
\text { outcome } \\
(\mathrm{N}=5)\end{array}$ & p value & $\begin{array}{l}\text { Favourable } \\
\text { outcome }^{\dagger} \\
(\mathrm{N}=28)\end{array}$ & $\begin{array}{l}\text { Adverse } \\
\text { outcome }^{\dagger} \\
(\mathrm{N}=7)\end{array}$ & p value \\
\hline \multirow{3}{*}{$\begin{array}{l}\text { Normal/ } \\
\text { subnormal } \\
\text { MRI }\end{array}$} & Normal & 15 & 0 & \multirow{6}{*}{$<0.001$} & 14 & 0 & \multirow{6}{*}{$<0.001$} \\
\hline & PPWMI & 9 & 0 & & 10 & 0 & \\
\hline & $\begin{array}{l}\text { Watershed } \\
\text { (W score } \leq 2 \text { ) }\end{array}$ & 2 & 0 & & 1 & 0 & \\
\hline \multirow{3}{*}{$\begin{array}{l}\text { Abnormal } \\
\text { MRI }\end{array}$} & $\begin{array}{l}\text { Watershed } \\
(\text { W score }>2 \text { ) }\end{array}$ & 0 & 0 & & 0 & 0 & \\
\hline & Central & 0 & 2 & & 2 & 4 & \\
\hline & Diffuse & 1 & 3 & & 1 & 3 & \\
\hline
\end{tabular}

Data are numbers of patients

$N=$ number of neonates, $P P W M I=$ punctate periventricular white matter injuries

Numbers in bold are false positives of MRI abnormalities in predicting adverse outcome 


\begin{tabular}{l|ll|lc} 
& \multicolumn{2}{|c|}{$\begin{array}{c}\text { All neonates with available follow-up } \\
\text { data }\end{array}$} & \multicolumn{2}{c}{$\begin{array}{c}\text { Neonates who had both MRIs } \\
\text { sequentially }\end{array}$} \\
\hline & Early MRI & Late MRI & Early MRI & Late MRI \\
& $\mathrm{N}=32$ & $\mathrm{~N}=35$ & $\mathrm{~N}=29$ & $\mathrm{~N}=29$ \\
$\mathrm{Se}$ & $\mathbf{1 0 0}(47.8-100)$ & $\mathbf{1 0 0}(59-100)$ & $\mathbf{1 0 0}(39.8-100)$ & $\mathbf{1 0 0}(39.8-100)$ \\
Sp & $\mathbf{9 6 . 3}(81-99.9)$ & $\mathbf{8 9 . 3}(71.8-97.7)$ & $\mathbf{9 6}(79.6-99.9)$ & $\mathbf{8 8}(68.8-97.5)$ \\
PPV & $\mathbf{8 3 . 3 ( 3 5 . 9 - 9 9 . 6 )}$ & $\mathbf{7 0}(34.8-93.3)$ & $\mathbf{8 0}(28.4-99.5)$ & $\mathbf{5 7 . 1}(18.4-90.1)$ \\
NPV & $\mathbf{1 0 0 ( 8 6 . 8 - 1 0 0 )}$ & $\mathbf{1 0 0}(86.3-100)$ & $\mathbf{1 0 0}(85.2-100)$ & $\mathbf{1 0 0}(84.6-100)$
\end{tabular}

Data are percentages (95\% confidence interval)

$N=$ number of neonates, $S e=$ sensitivity, $S p=$ specificity, $P P V=$ positive predictive value, $N P V=$ negative predictive value 


\begin{tabular}{llllllll}
\hline Region & AUC (95\% CI) & OR (95\% CI) & $\begin{array}{l}\text { Cut-off } \\
\left(\mathbf{1 0} / \mathbf{m m}^{2} / \mathbf{s}\right)\end{array}$ & Se (\%) & Sp (\%) & PPV (\%) & NPV (\%) \\
\hline PWM & $\mathbf{0 . 9 2 ( 0 . 7 7 - 0 . 9 9 )}$ & $0(0-0.29)$ & $\leq 1.35$ & 100 & 74.1 & 41.7 & 100 \\
SC & $\mathbf{0 . 8 7}(0.71-0.96)$ & $0(0-0.38)$ & $\leq 1.13$ & 80 & 88.9 & 57.1 & 96 \\
PLIC & $\mathbf{0 . 8 4}(0.66-0.94)$ & $0(0-0.54)$ & $\leq 0.96$ & 100 & 66.7 & 35.7 & 100 \\
CN & $\mathbf{0 . 8 2}(0.65-0.93)$ & $0(0-0.22)$ & $\leq 1.21$ & 100 & 55.6 & 29.4 & 100 \\
CP & $\mathbf{0 . 8 0}(0.63-0.92)$ & $0(0-1.66)$ & $\leq 1.05$ & 100 & 55.6 & 29.4 & 100 \\
LN & $\mathbf{0 . 7 9}(0.61-0.91)$ & $0(0-0.58)$ & $\leq 1.01$ & 80 & 74.1 & 36.4 & 95.2 \\
FWM & $\mathbf{0 . 7 7}(0.58-0.9)$ & $0(0-0.75)$ & $\leq 1.53$ & 80 & 66.7 & 30.8 & 94.7 \\
Thalami & $\mathbf{0 . 6 9}(0.5-0.84)$ & $0(0-0.42)$ & $\leq 0.82$ & 60 & 96.3 & 75 & 92.9 \\
\hline
\end{tabular}

$\overline{A D C}=$ apparent diffusion coefficient, $A U C=$ area under curve, $C I=$ confidence interval, OR $=$ odds ratio, $P W M=$ posterior white matter,$S C=$ semi-oval centres, $P L I C=$ posterior limb of internal capsule, $C N=$ head of caudate nuclei, $C P=$ cerebral peduncles, $L N=$ lentiform nuclei, $F W M=$ frontal white matter, $S e=$ sensitivity, $S p=$ specificity, $P P V=$ positive predictive value, $N P V=$ negative predictive value 


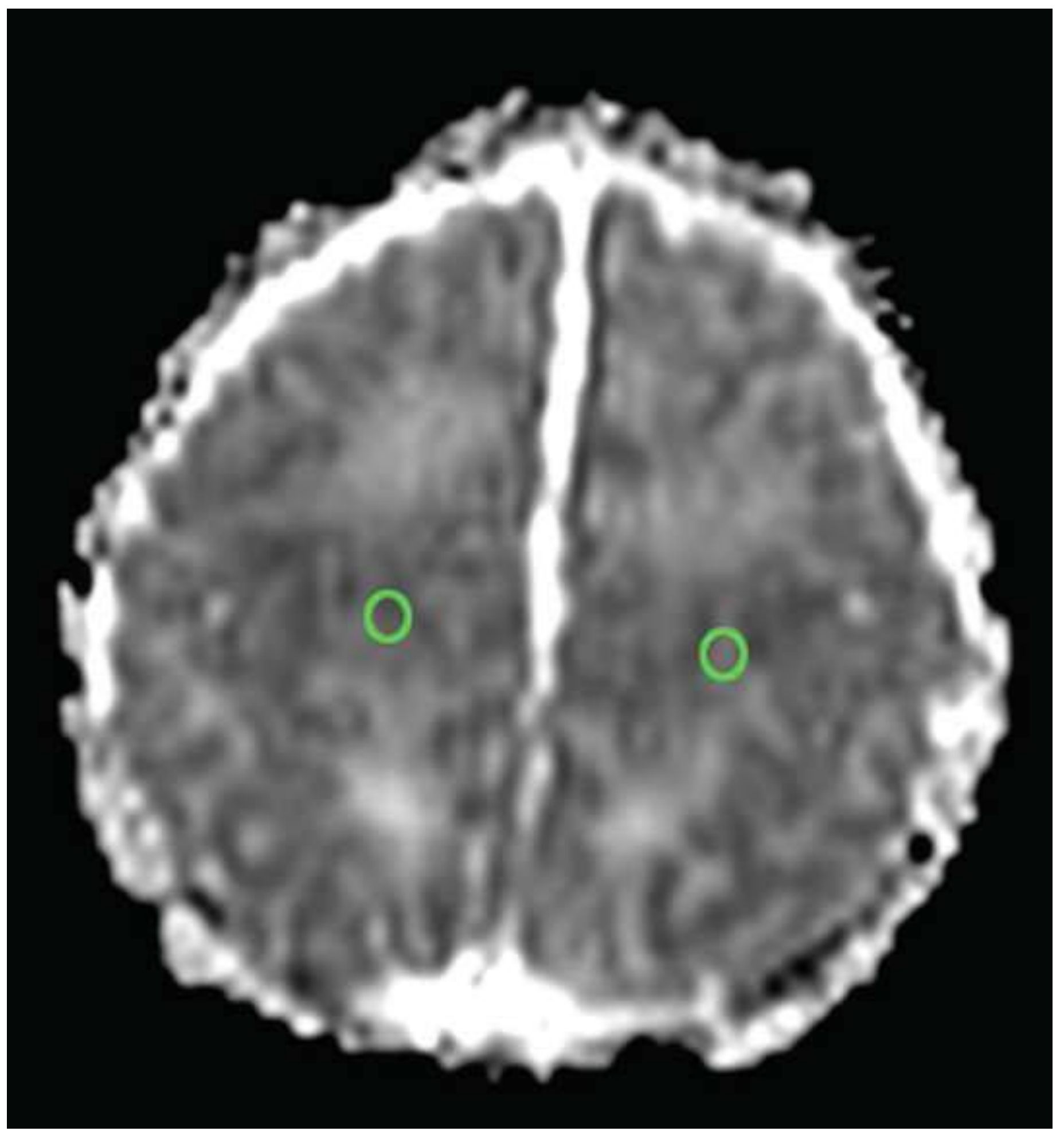




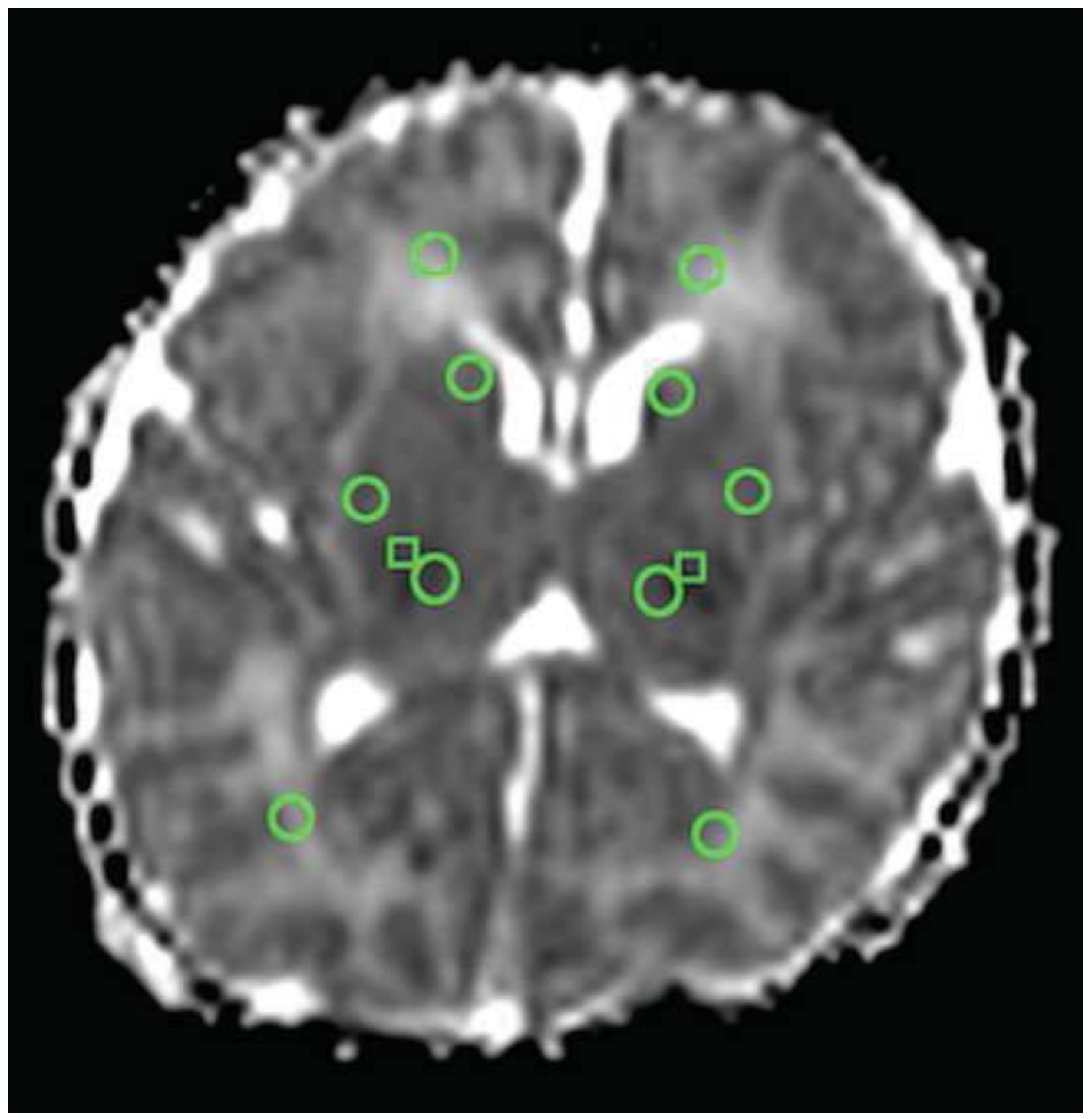




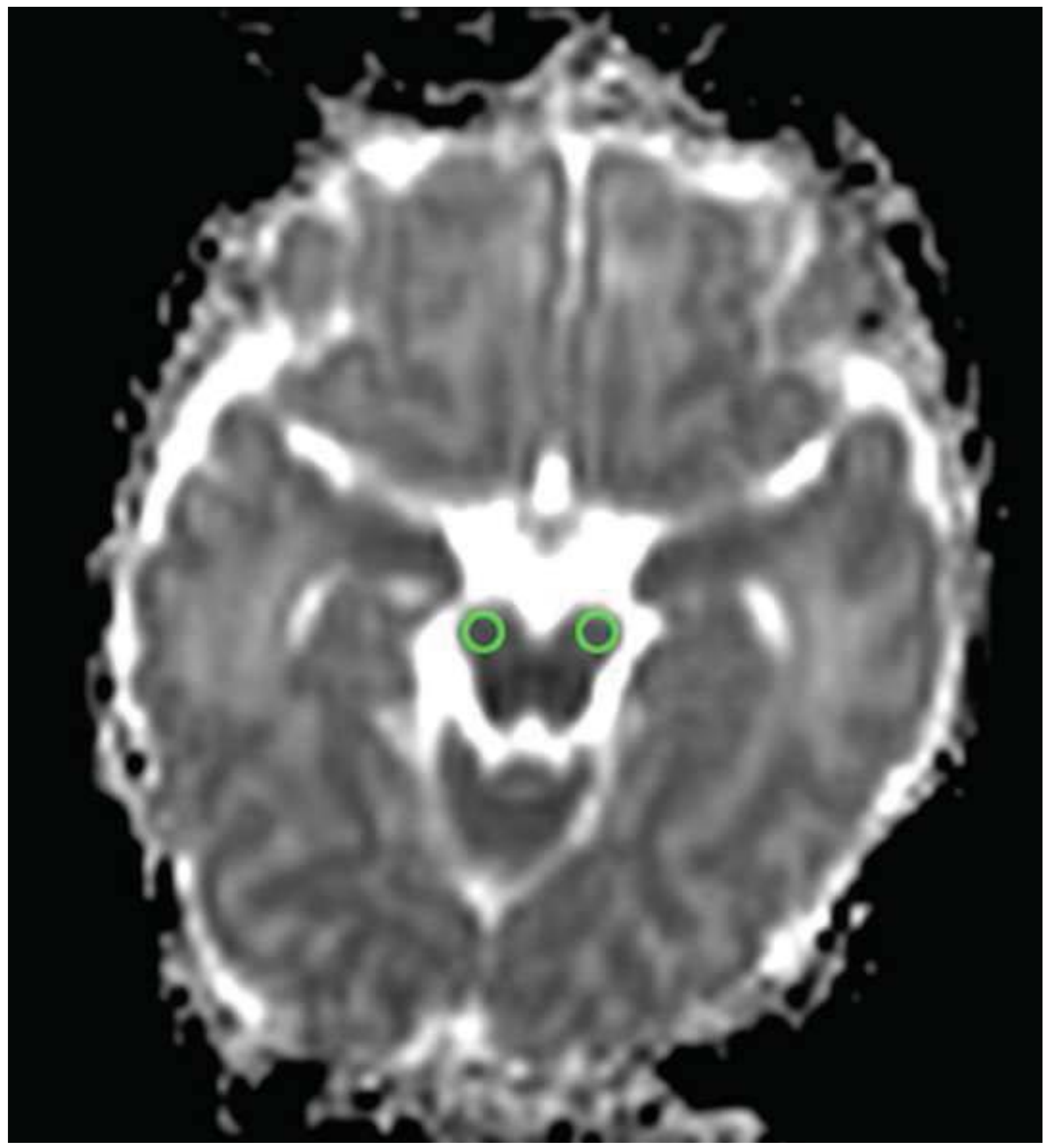




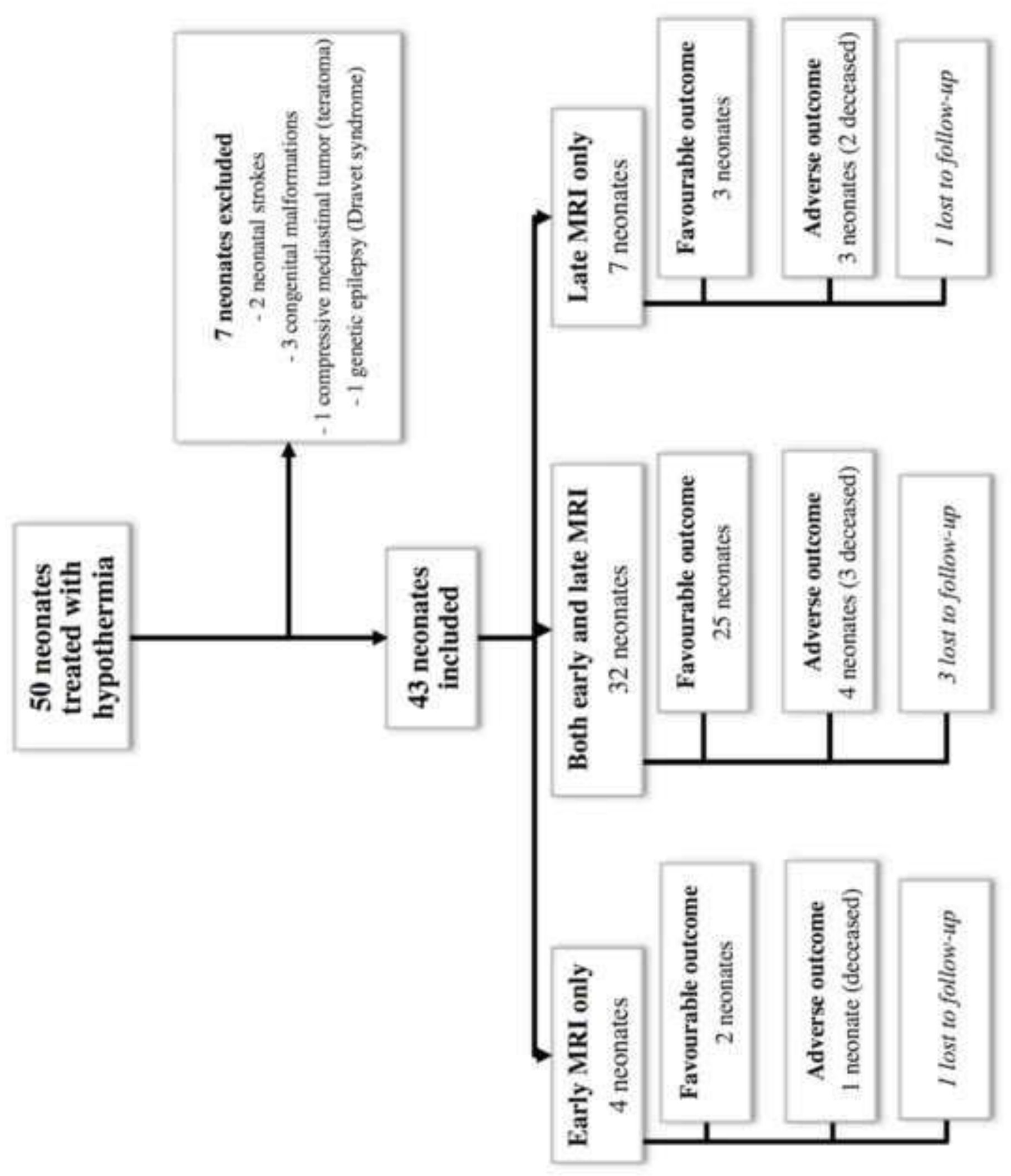

$N$
는
$\frac{3}{5}$
은 


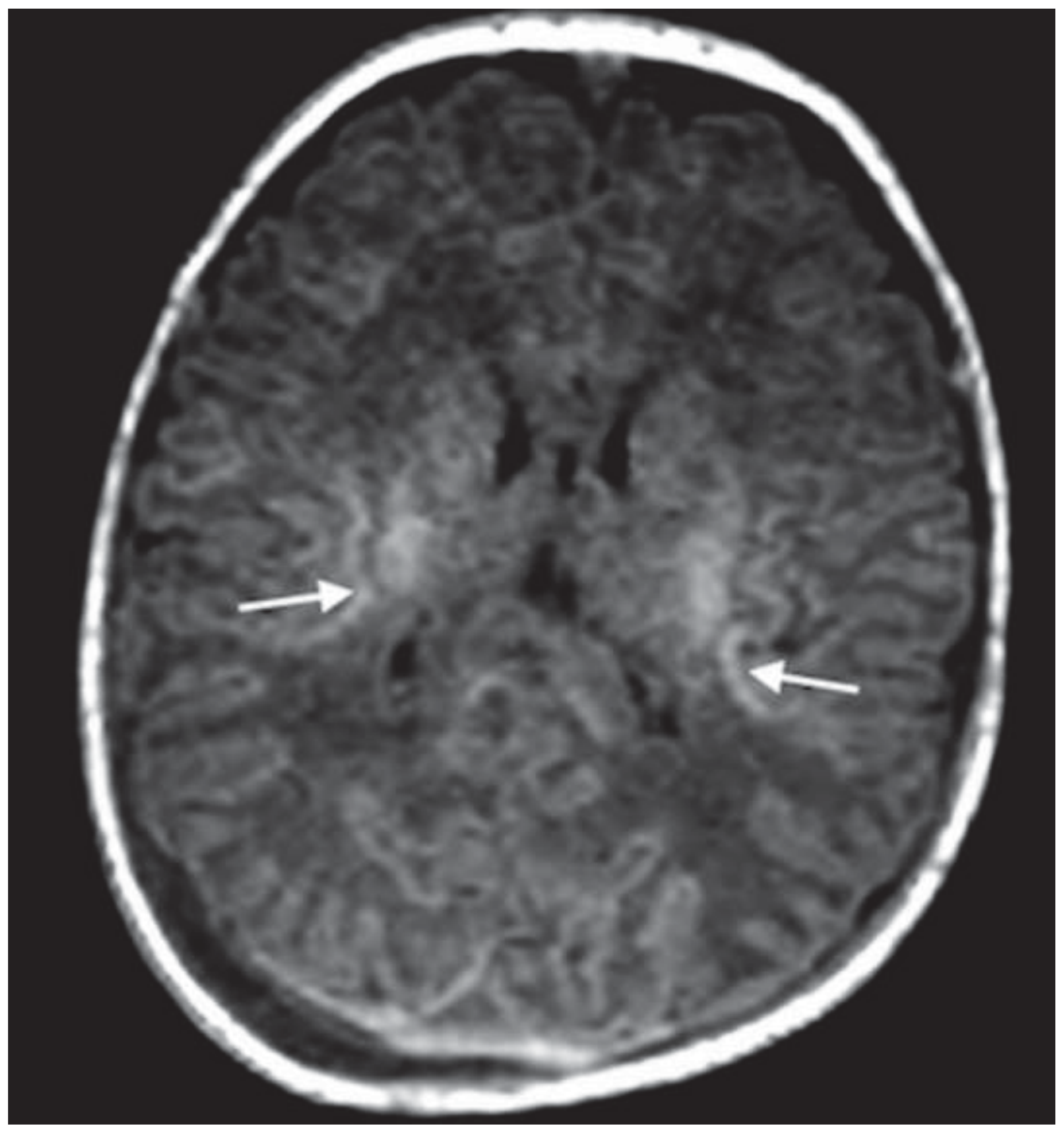




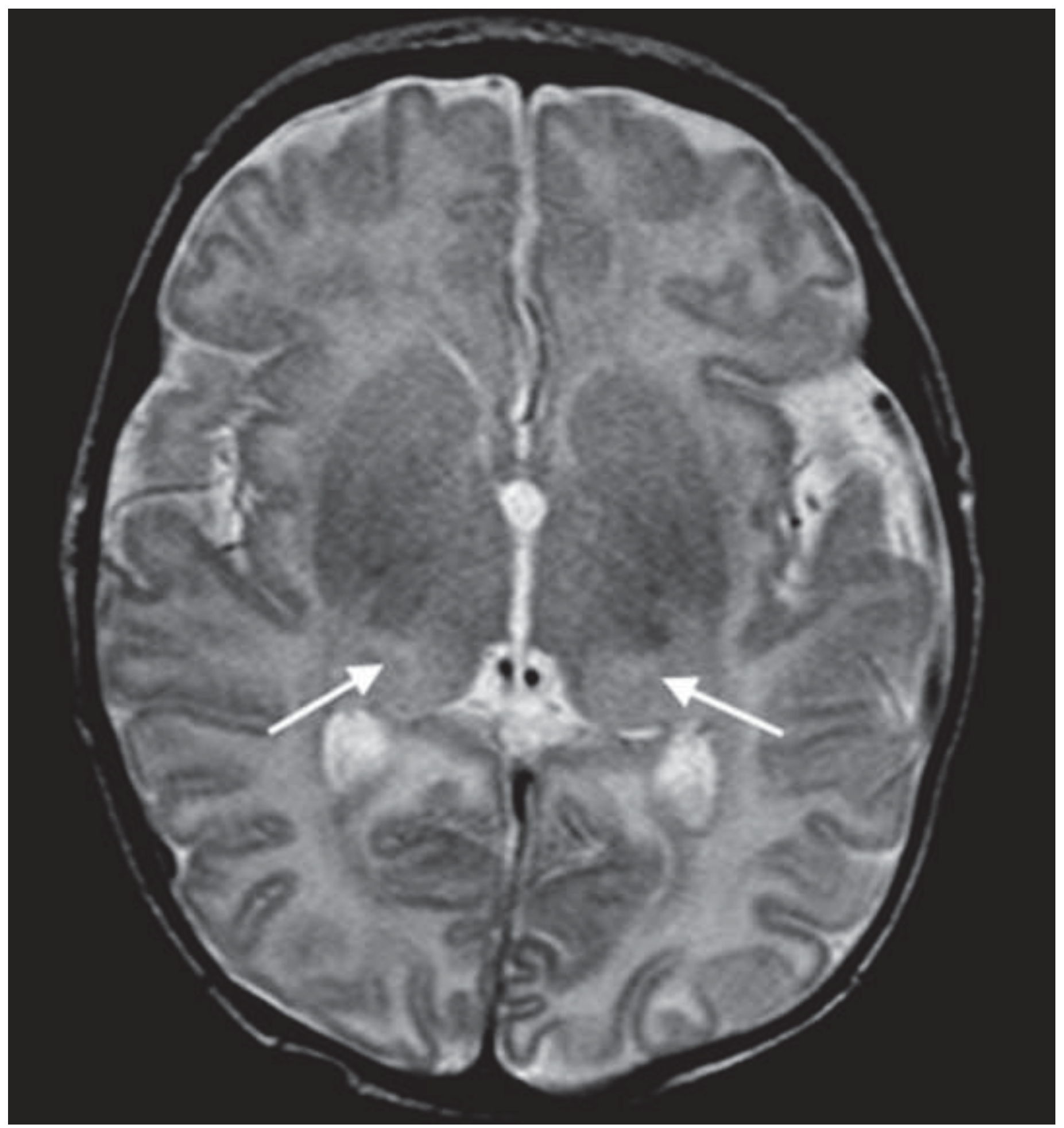




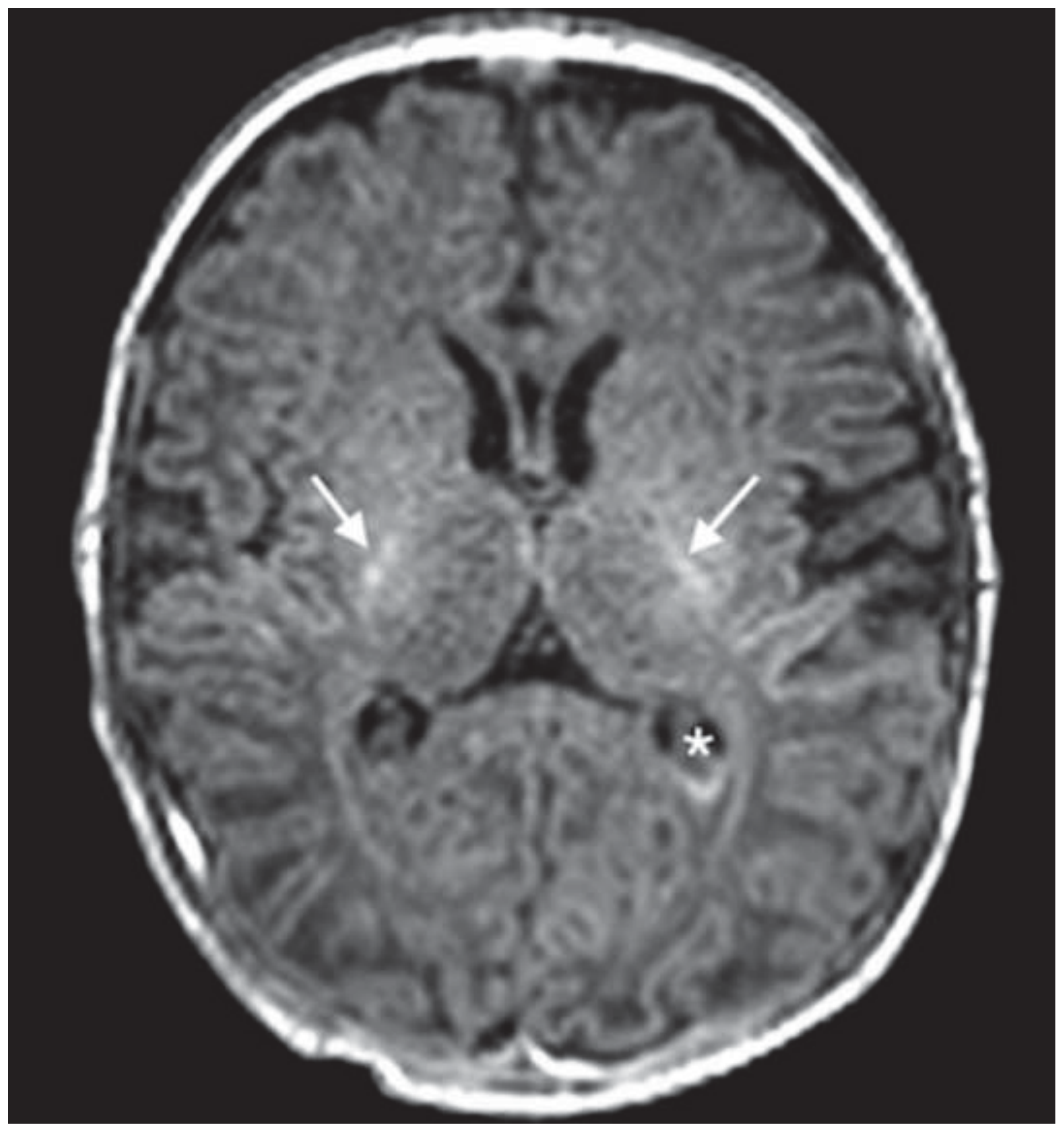




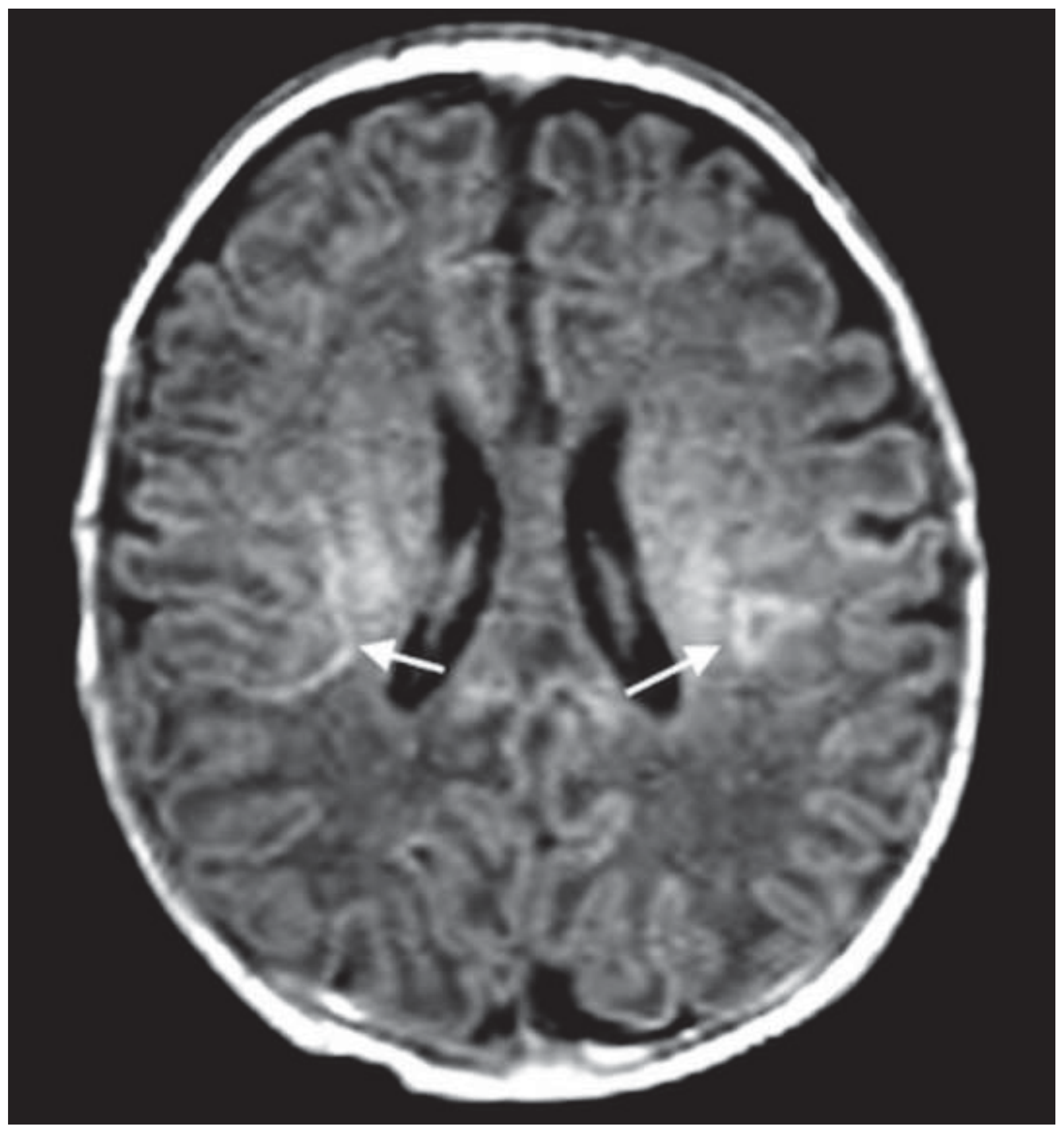




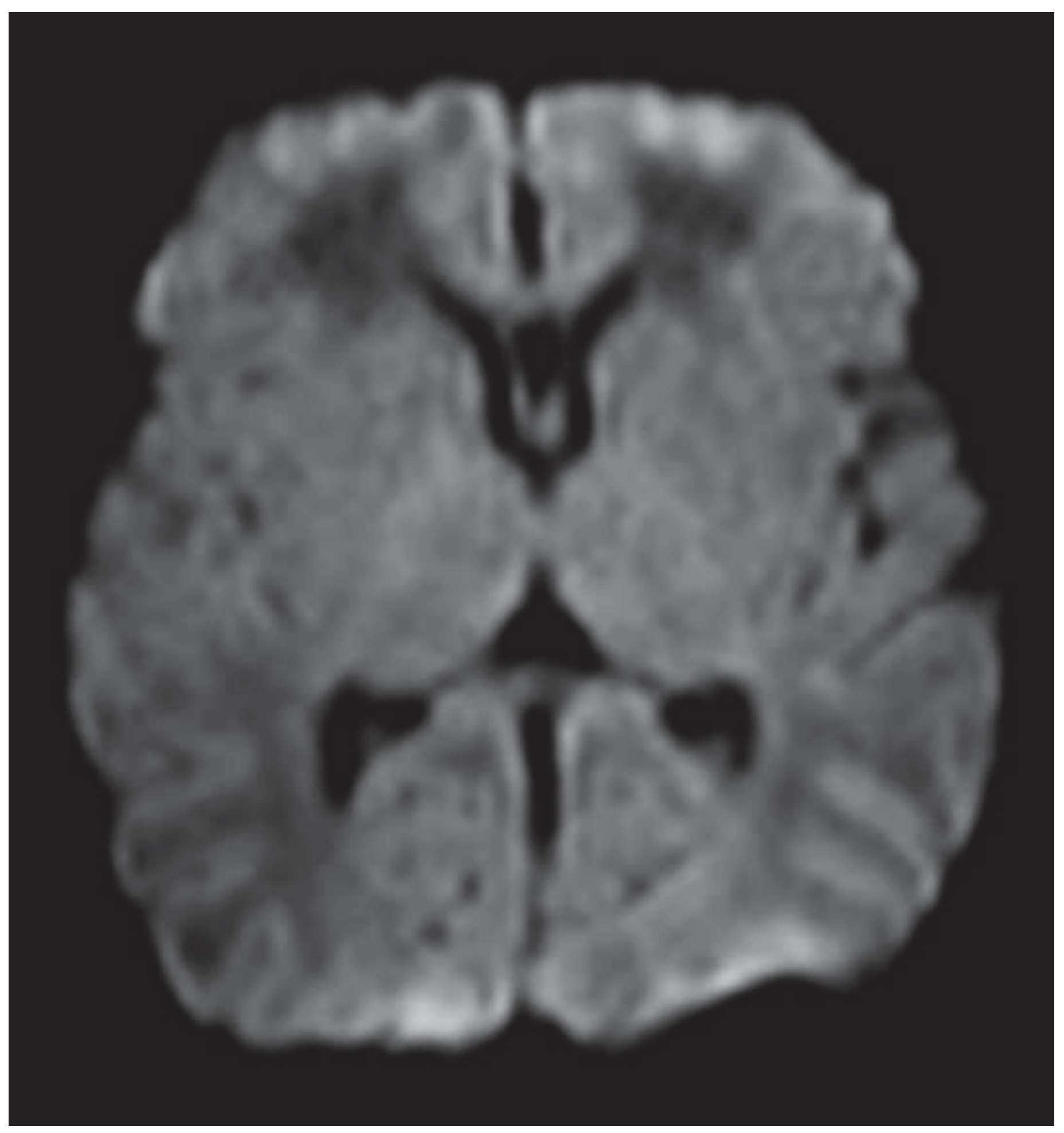




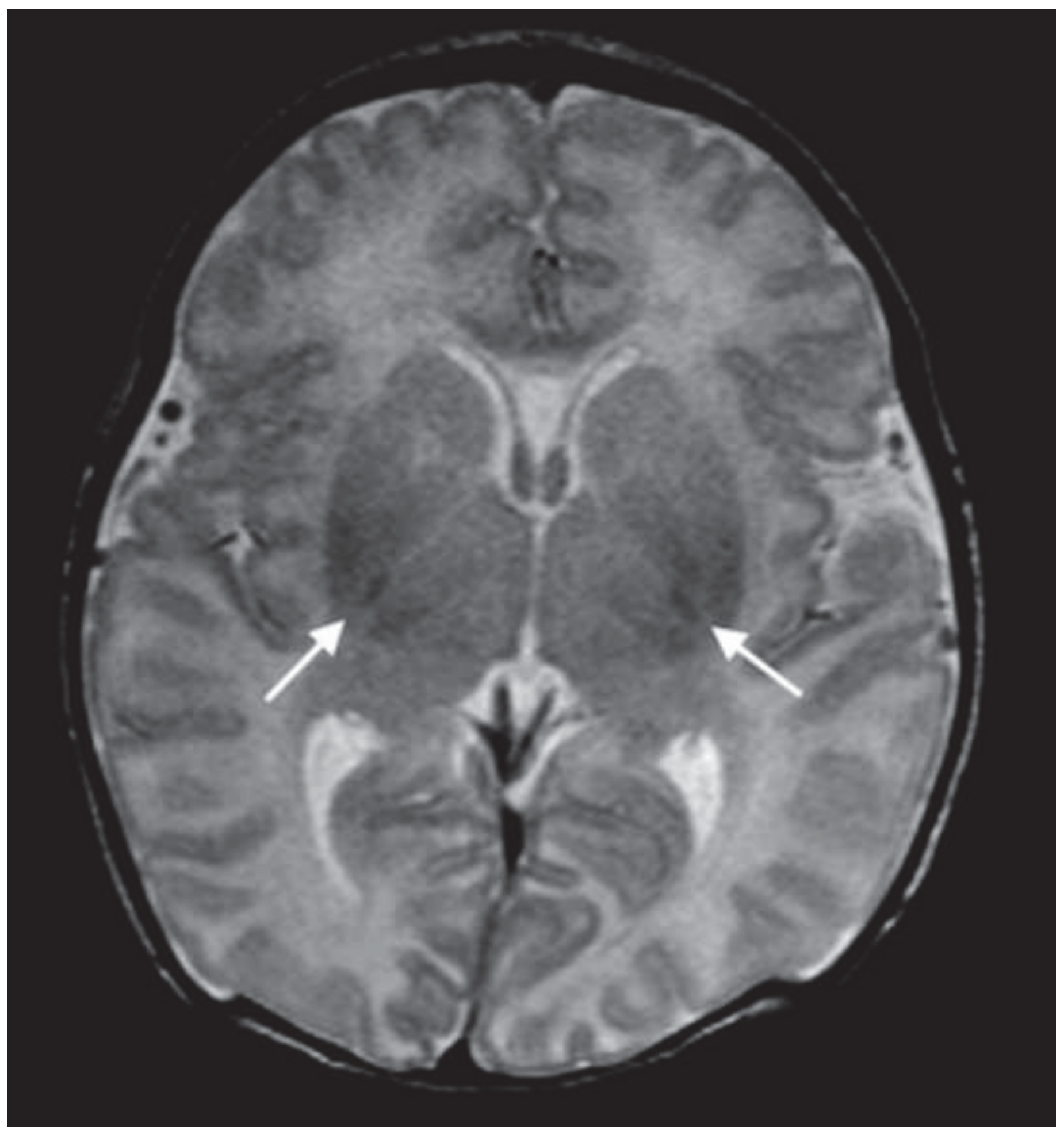




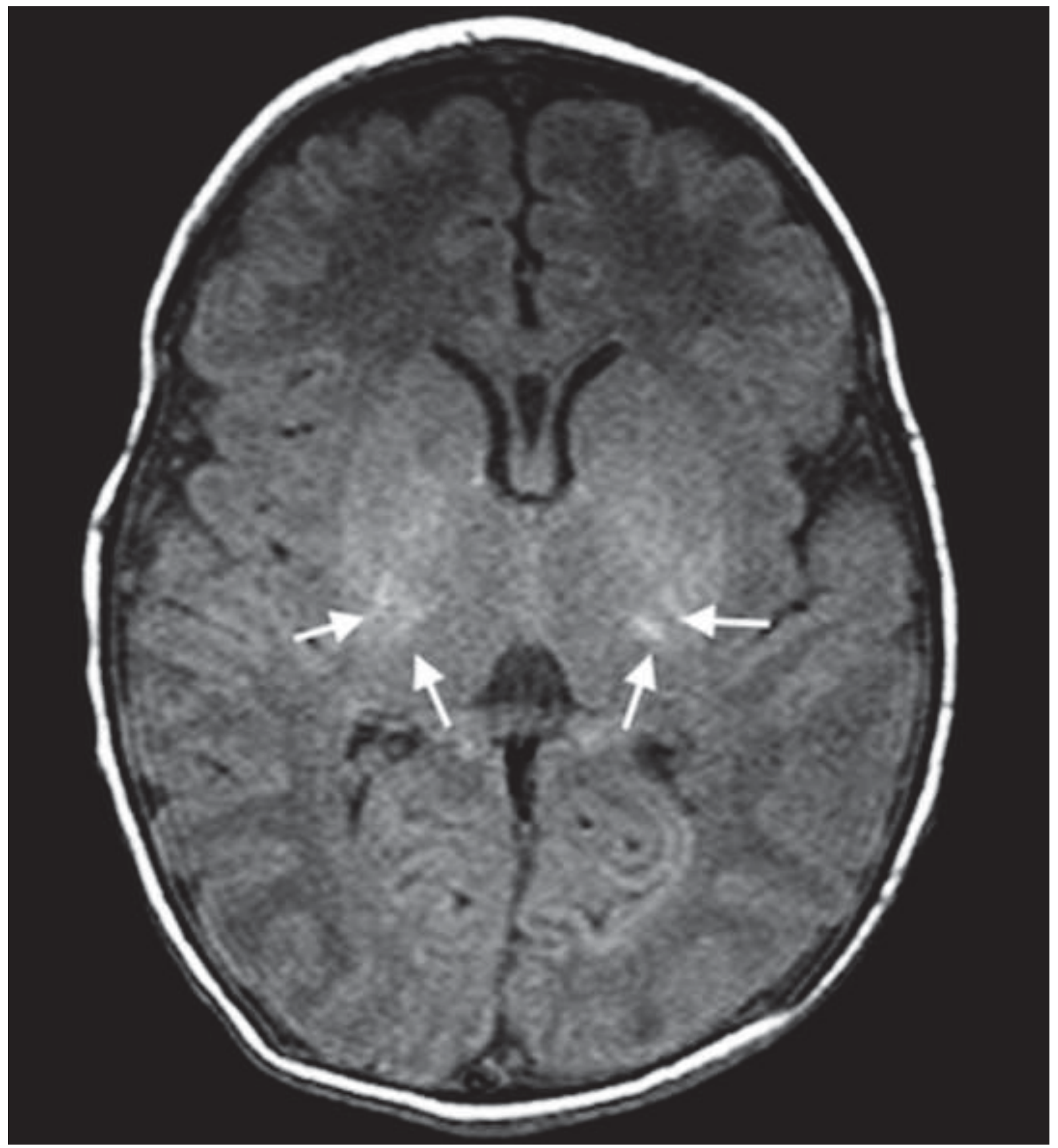




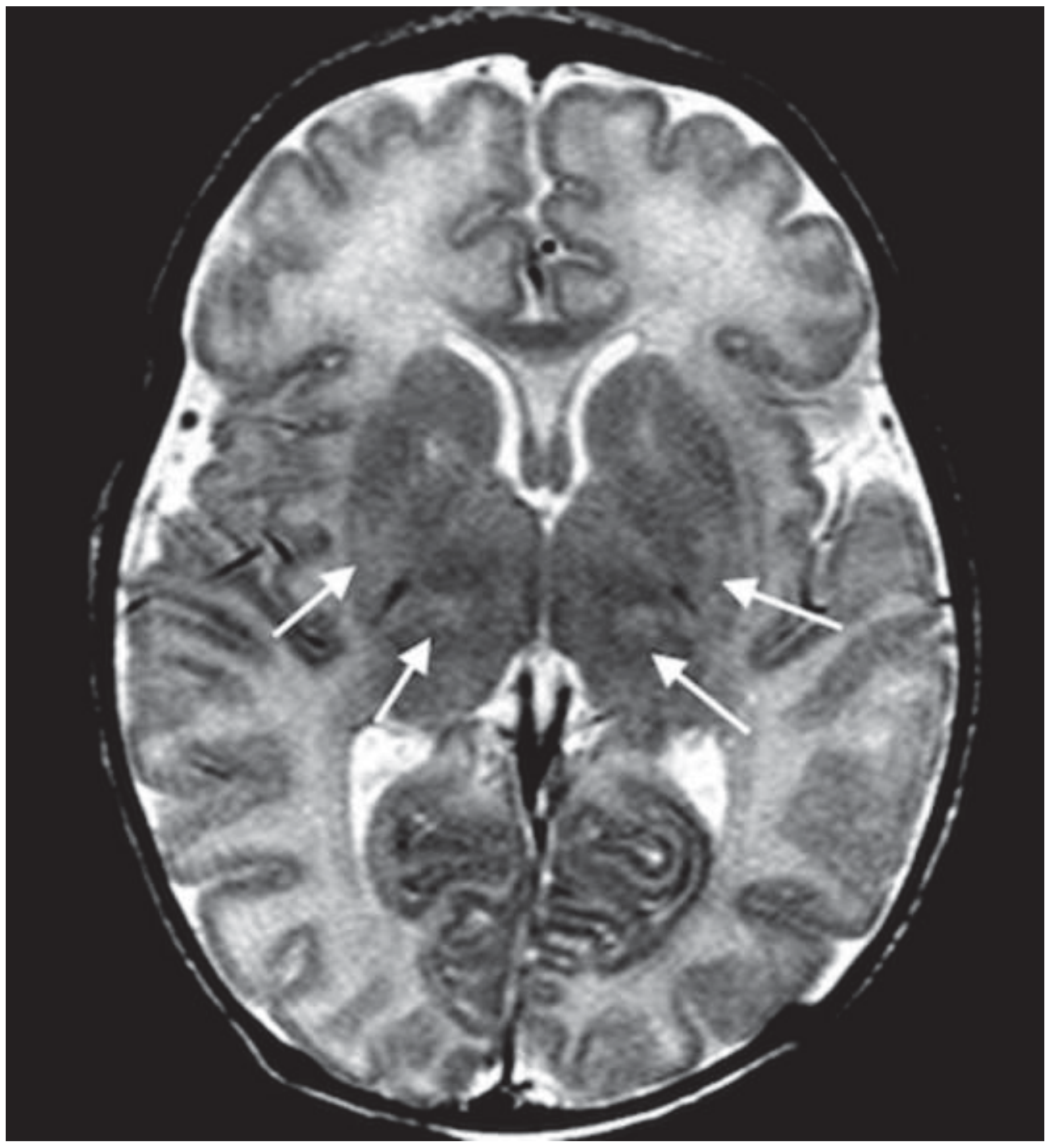




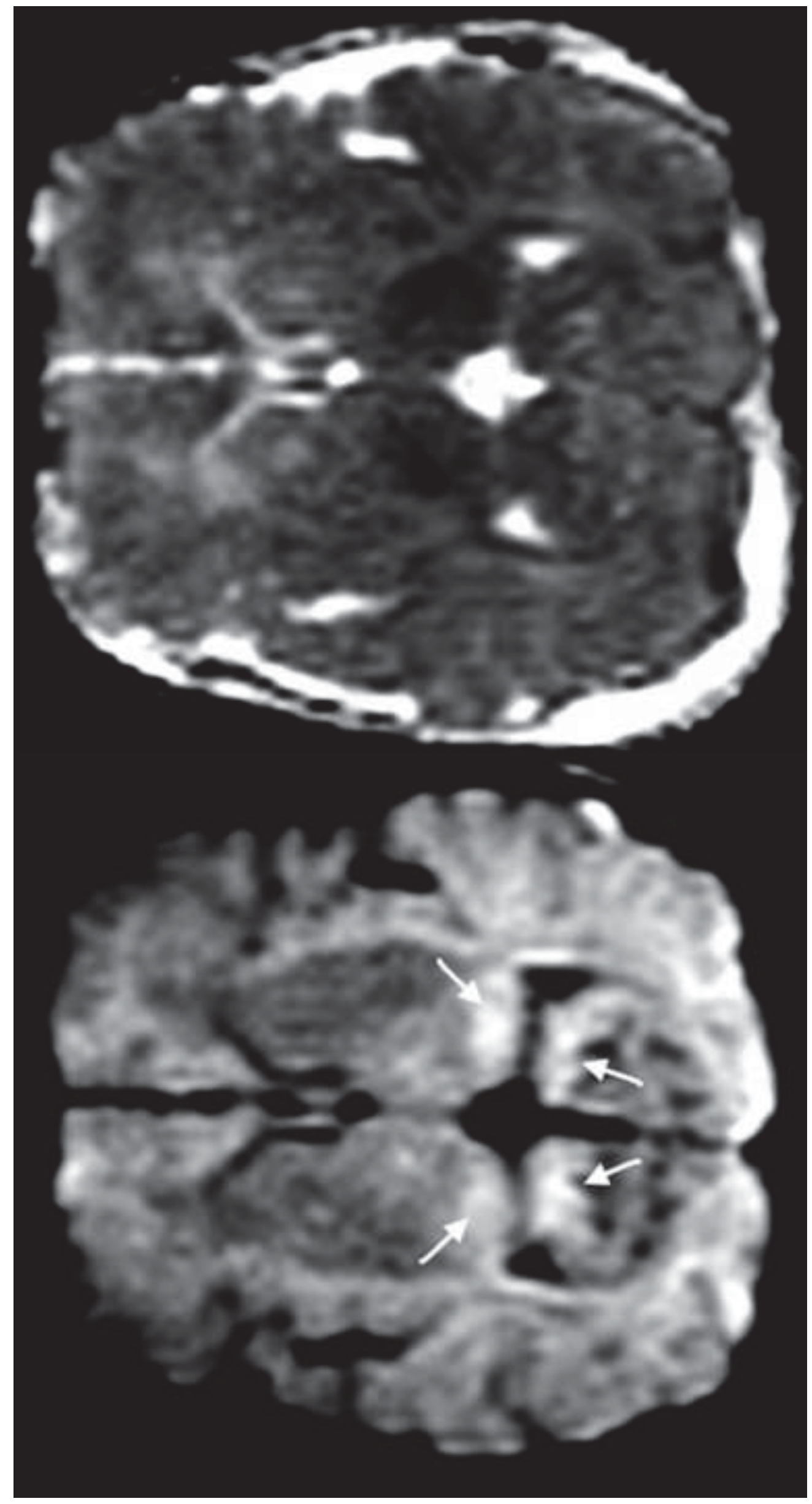




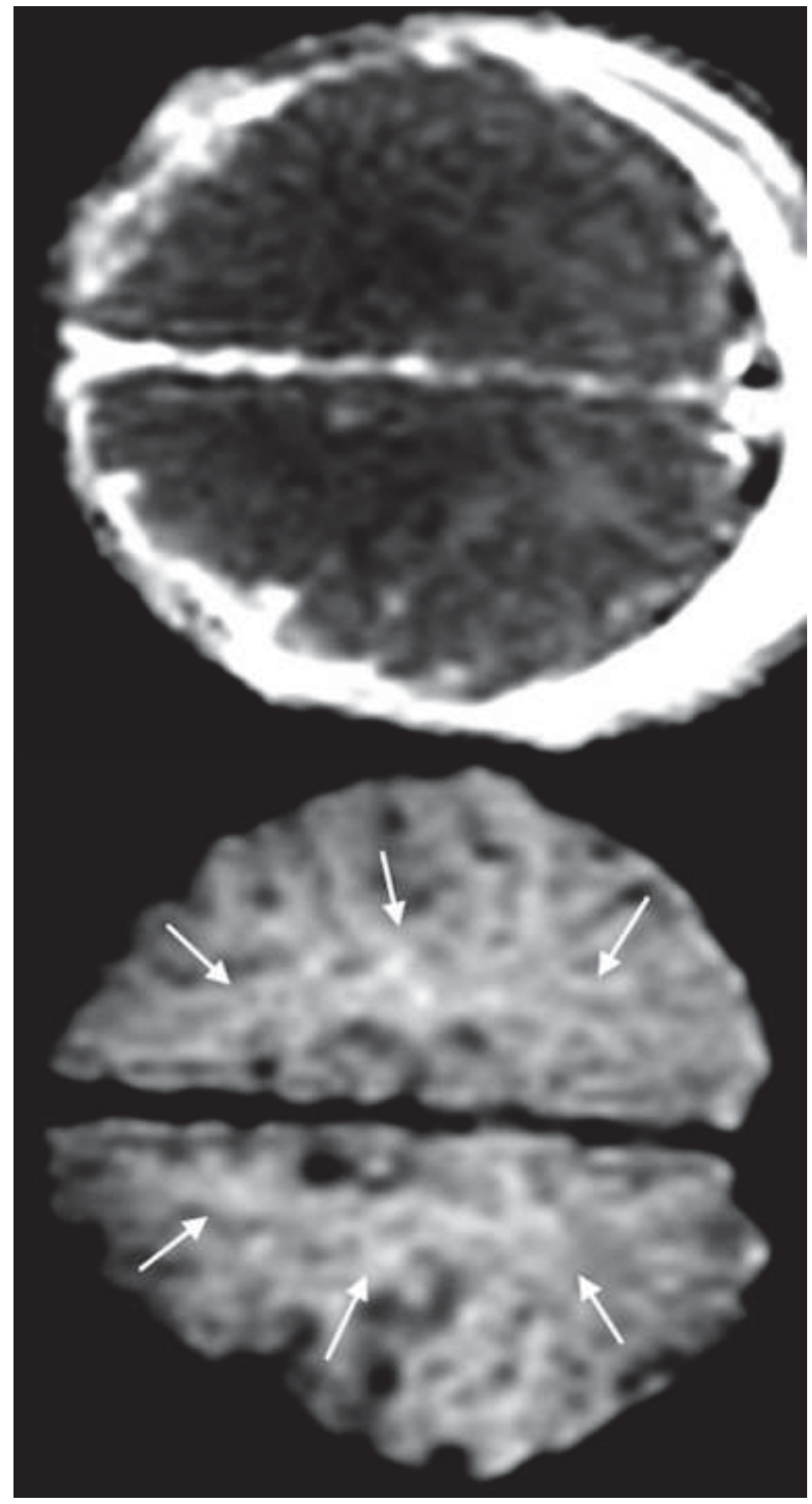




\section{APPENDIX}

\section{Description of the simplified classification and patterns of injury}

\begin{tabular}{|c|c|c|}
\hline \multirow{3}{*}{$\begin{array}{l}\text { Normal/ } \\
\text { subnormal } \\
\text { MRI }\end{array}$} & Normal MRI & No signal abnormality in the entire brain \\
\hline & $\begin{array}{l}\text { Punctate periventricular } \\
\text { white matter injuries }\end{array}$ & $\begin{array}{l}\text { Punctate or small confluent periventricular }<1 \mathrm{~cm} \text { white } \\
\text { matter signal abnormalities }\end{array}$ \\
\hline & $\begin{array}{l}\text { Watershed injuries with a } \\
\text { W score } \bullet 2\end{array}$ & $\begin{array}{l}\text { Single infarction or abnormal signal in anterior or } \\
\text { posterior white matter (except punctate periventricular) in } \\
\text { the intravascular boundary zones, without central or } \\
\text { diffuse pattern criteria }\end{array}$ \\
\hline \multirow{3}{*}{$\begin{array}{l}\text { Abnormal } \\
\text { MRI }\end{array}$} & $\begin{array}{l}\text { Watershed injuries with a } \\
\text { W score }>2\end{array}$ & $\begin{array}{l}\text { More extensive watershed injuries, involving anterior and } \\
\text { posterior white matter or white matter and cortex in the } \\
\text { intravascular boundary zones (except single infarction, } \\
\text { central and diffuse patterns) }\end{array}$ \\
\hline & Central injuries & $\begin{array}{l}\text { Signal abnormalities in at least one of the following } \\
\text { regions: lentiform nucleus, caudate nucleus, thalamus, } \\
\text { perirolandic cortex, cerebral peduncle, hippocampus, } \\
\text { without diffuse pattern criteria }\end{array}$ \\
\hline & Diffuse injuries & $\begin{array}{l}\text { Diffuse white matter signal abnormalities involving at } \\
\text { least } 4 \text { lobes and/or cortical injuries involving more than } \\
\text { the perirolandic cortex or watershed cortex, and/or } \\
\text { watershed and central pattern criteria }\end{array}$ \\
\hline
\end{tabular}

